\title{
PEMBEKUAN UDANG MERAH (Panaseus monodon) PRODUK HEAD LESS SKALA RUMAH TANGGA DI BAGANSIAPIAPI KABUPATEN ROKAN HILIR
}

\author{
Basri $^{1}$, Muh Suryono ${ }^{1}$ Aji Sumantri Putra ${ }^{2}$ \\ ${ }^{1}$ Dosen Jurusan Pengolahan Hasil Laut Poltek KP Dumai \\ ${ }^{2}$ Taruna Jurusan Pengolahan Hasil Laut Poltek KP Dumai \\ *Email: tanjungbasri29@gmail.com
}

\begin{abstract}
ABSTRAK
Udang merupakan hewan yang hidup di perairan, khususnya sungai, laut, atau danau. Udang dapat ditemukan di hampir semua genangan air yang berukuran besar baik air tawar, air payau, maupun air asin. Udang Merah (Paneus monodon) merupakan salah satu komoditas unggulan Indonesia dalam upaya menghasilkan devisa negara yang berasal dari kelompok non migas. Kondisi laut yang luas dan iklim tropis Indonesia mendukung pertumbuhan dan perkembangan udang merah (Paneus monodon). Pembekuan adalah proses penggunaan suhu rendah dibawah $0^{\circ} \mathrm{C}$ dimana selama proses pembekuan berlangsung, terjadi perpindahan panas dari tubuh udang yang bersuhu lebih tinggi ke refriferant yang bersuhu rendah. Metode yang digunakan dalam penelitian ini adalah metode survei yaitu melakukan pengamatan langsung dan aktif melakukan praktik langsung di lapangan pada objek-objek pendederan udang merah (Paneusmonodon). Hasil penelitian didapatkan bahwa dalam melakukan pengolahan pembekuan udang merah terdapat beberapa tahap yang harus dilakukan yaitu penerimaan bahan baku, penimbangan, pencucian awal, pemotongan kepala, pencucian kedua, penimbangan, sortasi, penyusunan, pembekuan, dan pelabelan serta pemasaran produk. Desain kemasan yang baik dan benar harus memperhatikan pemilihan warna, font, ukuran dan bahan yang tepat dan sesuai. Selain itu di dalam label juga harus terdapat beberapa keterangan seperti nama produk, daftar bahan yang digunakan, berat atau isi bersih, nama dan alamat pihak yang memproduksi atau memasukan pangan kedalam wilayah Indonesia baik tanggal, bulan dan tahun kadaluwarsanya. Dilihat dari analisis usaha menunjukan bahwa pembekuan udang merah menguntungkan.
\end{abstract}

Kata Kunci: Bagansiapi-api, Udang Merah, Paneus monodon, Pembekuan.

\begin{abstract}
Shrimp are animals that live in waters, especially rivers, seas, or lakes. Shrimp can be found in almost all large puddles of fresh water, brackish water, and salt water. Red Shrimp (Paneus monodon) is one of Indonesia's leading commodities in an effort to generate foreign exchange from the non-oil group. The vast sea conditions and tropical climate of Indonesia support the growth and development of red shrimp (Paneus monodon). Freezing is the process of using a low temperature below $0 \mathrm{oC}$ where during the freezing process, heat transfer occurs from the shrimp body with a higher temperature to a lower temperature refrigerant. The method used in this study is a survey method, namely direct observation and active direct practice in the field on nursery objects of red shrimp (Paneus monodon). The results showed that in processing red shrimp freezing there were several steps that must
\end{abstract}


be carried out, namely receiving raw materials, weighing, initial washing, cutting heads, second washing, weighing, sorting, compiling, freezing, and labeling and marketing products. A good and correct packaging design must pay attention to the right and appropriate selection of colors, fonts, sizes and materials. In addition, the label must also contain several information such as the name of the product, a list of materials used, net weight or content, the name and address of the party producing or importing food into the territory of Indonesia, including the date, month and year of expiration. Judging from the business analysis shows that freezing red shrimp is profitable.

Keywords : Bagansiapi-api, Red Shrimp, Paneus monodon, Freezing

\section{PENDAHULUAN}

Udang merupakan hewan yang hidup di perairan, khususnya sungai, laut, atau danau. Udang dapat ditemukan di hampir semua "genangan" air yang berukuran besar baik air tawar, air payau, maupun air asin pada kedalaman bervariasi, dari dekat permukaan hingga beberapa ribu meter di bawah permukaan.Salah satunya adalah udang merah (Paneus monodon) udang ini sering disebut giant tiger yang artinya Harimau raksasa karena udang ini memiliki bentuk belang - belang dan ukurannya cukup besar dibanding udang lainnya.

Udang merah (Paneus monodon) berubah bentuk menjadi kristal es. Pembekuan juga bertujuan mengawetkan sifat-sifat alami dengan cara menghambat aktivitas bakteri dan enzim. Pembekuan juga merupakan suatu cara pengawetan bahan pangan dengan cara membekukan bahan dibawah suhu titik beku tersebut.

Ada berbagai macam peralatan pembekuan yang selama ini digunakan, salah satunya yaitu alat pembeku komersial yang lazim dikenal sebagai freezer. Penggunaan freezer sangat popoler, Baik untuk skala rumah tangga maupun industri pengolahan kecil dan kegiatan penelitian.Pada kegiatan penelitian misalnya,freezer digunakan untuk menyimpan sampel atau produk yang memerlukan proses lanjutan. Salah satu titik krisis dari freezer ini adalah ketidak seragaman pada suhu antar posisi pada ruang merupakan salah satu komoditas unggulan Indonesia dalam upaya menghasilkan devisa negara yang berasal dari kelompok non mogas. Kondisi laut yang luas dan iklim tropis Indonesia mendukung pertumbuhan dan perkembangan udang merah (Paneus monodon ).

Pembekuan adalah proses penggunaan suhu rendah dibawah $0^{\circ} \mathrm{C}$ dimana selama proses pembekuan berlangsung, terjadi perpindahan panas dari tubuh udang yang bersuhu lebih tinggi ke refriferant yang bersuhu rendah. Dengan demikian kandungan air dalam tubuh udang akan penyimpanan beku serta perbedaan suhu real time dengan suhu setting. Akibatnya produk dapat mengalami kemunduran mutu,hal ini berkaitan dengan ketersediaan slot pada freezer. Tujuan dilakukannya penelitian ini adalah sebagai berikut : memahami proses pembekuan udang merah (Paneus monodon) secara modern, untuk meningkatkan pengetahuan dan keterampilan dalam pembekuan udang, untuk mengetahui analisa usaha dari pembekuan udang merah (Paneus monodon), dan untuk mengetahui desain kemasan yang baik dan benar. 
SEMAH : Journal Pengelolaan Sumberdaya Perairan http://ojs.umb-bungo.ac.id/index.php/SEMAHJPSP VOL. 4 No. 2

ISSN : 2580-0736

Desember 2020

\section{METODE PENELITIAN}

Penelitian dilaksanakan selama 1 bulan pada tanggal 6 Juli sampai 6 Agustus 2020 di Bagansiapiapi, Kabupaten Rokan Hilir Provinsi Riau. Alat dan bahan merupakan 2 hal yang sangat penting dan Tabel 2.Peralatan Pembekuan Udang Merah

\begin{tabular}{cll}
\hline No & \multicolumn{1}{c}{ Peralatan } & \multicolumn{1}{c}{ Fungsi } \\
\hline 1 & Keranjang & Untuk menyaring air sisa pencucian Udang \\
2 & Baskom & Wadah meletakan Udang \\
3 & Pan & Untuk meletakan udang \\
4 & Timbangan & Menimbang berat Udang \\
5 & Lemari Es & Alat pembekuan Udang \\
6 & Sarung tangan & \\
7 & Masker & Untuk melindungi \\
& & Untuk menutup Mulut \\
\hline
\end{tabular}

Sumber : Data primer

Tabel 3.Bahan dan Alat pengujian Organoleptik

\begin{tabular}{cll}
\hline No & \multicolumn{1}{c}{ Bahan } & \multicolumn{1}{c}{ Fungsi } \\
\hline 1 & Udang Merah & Bahan Baku Utama pemberuan \\
2 & Kemasan Plastik & Sebagai bahan mengemas produk \\
3 & Label Kemasan & Sebagai bahan penanda produk \\
4 & Air Bersih & Untuk membersikan udang \\
5 & Lembar Skor & Sebagai alat untuk penilaian \\
6 & Pena & Sebagai alat untuk menulis Skor \\
& & Sebagai alat untuk menampung sampel \\
7 & Piring & Sebagai alat untuk kontak dengan sampel \\
\hline
\end{tabular}

Sumber : Data primer

Metode yang digunakan dalam penelitian ini adalah metode survei yaitu melakukan pengamatan langsung dan aktif melakukan praktik langsung di lapangan pada objek-objek pendederan udang merah (Paneus monodon). menjadi pokok utama dalam pelaksanaan Penelitian. Dalam pembekuan udang merah terdapat beberapa alat dan bahan yang diguanakan sebagai berikut:

Untuk menutup Mulut 
modern.

2) Diskusi, untuk mengidentifikasi permasalahan yang terjadi dalam usahadagang perikanan.
3) Wawancara, untuk memperoleh informasi yang berkaitan dengan kegiatan pengolahan modern.

\section{HASIL DAN PEMBAHASAN}

Adapun prosedur kerja pembekuan udang merah ini adalah :

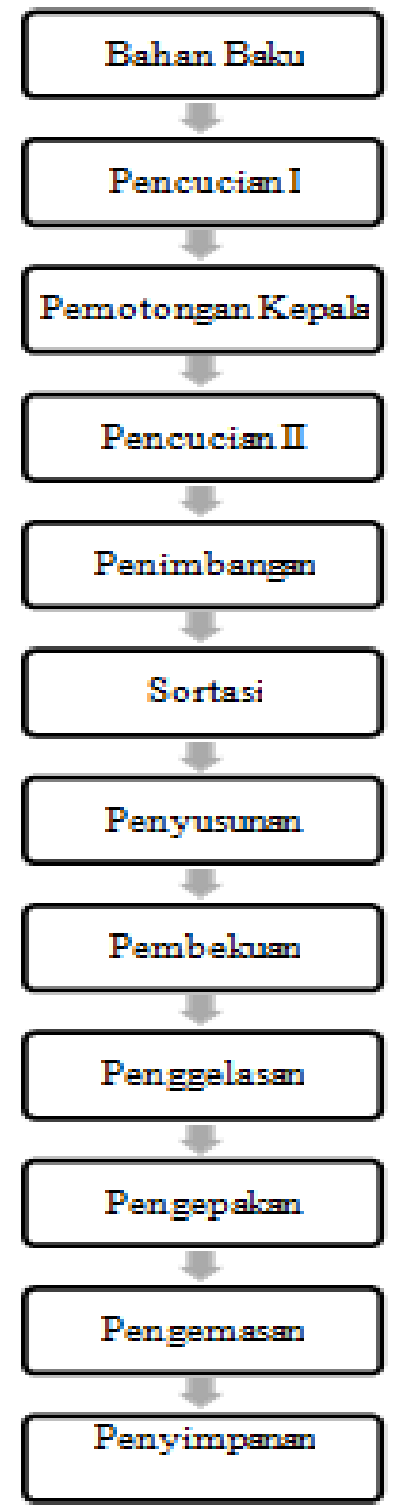

Gambar. 1 Alir Proses pembekuan Udang 


\section{Uji Organoleptik}

Lembaran penilaian sensori Udang Merah Beku (Penilaian sensori dengan SNI 01-2346-2006) tentang penunjuk pengujia organoleptic dan sensori adapun berikut penilaian nya :

1. Mastura $=$ Usia 20

A. Dalam keadaan beku

-Lapisan es : 8

-Pengeringan (dehidrasi) :7

-Perubahan warna (diskolorasi) : 9

B. Sesudah pelelehan (thawing)

- Kenampakan : 9

- Bau : 9

- Daging (warna dan kenampakan) : 9

2. Anjely = Usia 15

A. Dalam keadaan beku

-Lapisan Es : 8

-Pengeringan (dehidrasi): 7

-Perubahan warna: 9

$B$. Sesudah pelelehan (thawing)

- Kenampakan : 7

-Bau: 7

-Daging(warna ): 7

\section{Analisa Usaha}

Analisa usaha adalah kegiatan untuk menilai sejauh mana manfaat yang dapat diperoleh dalam meleksanakan suatu kegiatan usaha. Hasil analisisis ini digunakan sebagai bahan pertimbangan dalam mengambil keputusan, apakah menirima atau menolak dari suatu gagasan usaha.

Analisa laba rugi \laba

Rugi $\backslash$ laba $=$ total penjualan - total biaya

$$
\begin{aligned}
& =30.000-25.000 \\
& =5000
\end{aligned}
$$

Hasil analisa di atas menujukan bahwa usaha pembekuan Udang Merah dalam jangka waktu 1 hari akan menghasilkan keuntungan sebesar $\mathrm{Rp}$ 5000. Suatu usaha, nilai yang diperoleh
3. Adil : Usia 24

A. Dalam keadaan beku

- Lapisan es : 9

- Pengeringan (dehidrasi) : 8

- Perubahan warna : 9

B. Sesudah pelelehan (thawing)

-kenampakan : 7

-Bau : 7

-Daging(warna ) 9

4. Syifa $=$ Usia 22

A. Dalam keadaan beku

-Lapisan es: 9

-pengeringan (dehidrasi): 8

-perubahan warna : 9

$B$. sesudah pelelehan (thawing)

-kenampakan : 7

-Bau : 7

-Daging (warna ) : 9 sebesar 1,53, hal itu menunjukkan bahwa produk layak untuk dijalankan. karena lebih dari 1, menurut Effendi (2006), Suatu usaha dikatakan layak bila R/C lebih besar dari 1 (R/C>1), dan yang terakhir adalah analisa Break Even Point (BEP), analisis BEP atau titik impas adalah sebuah teknik yang berguna dalam menentukan banyaknya unit yang terjual atau harga untuk mencapai titik impas (Muchson, 2017). BEP terbagi menjadi dua yaitu BEP harga dan BEP produksi, BEP harga menunjukkan harga terendah dari produk yang dihasilkan sedangkan BEP produksi adalah menggambarkan produksi minimal yang harus dihasilkan. BEP harga dari usaha pembekuan udang ini adalah Rp 5000, sedangkan BEP produksi adalah sebanyak 1 packs. 


\section{Desain Kemasan}

Menurut Muftreni (2016), Kemasan adalah salah satu kunci dalam menjaga kualitas produk, yang berarti, kemasan melibatkan kegiatan mendesain dan memproduksi, untuk melindungi produk. Kemasan selalu melibatkan design agar pesan produk tersampaikan kepada konsumen, fungsi kemasan sendiri saat ini selain untuk melindungi produk juga berfungsi sebagai media pemasaran yang jitu. Terdapat 6 elemen yang harus dipenuhi ketika membuat desain produk yaitu, ukuran, bentuk, material bahan, warna, text dan merk. Warna berperan penting dalam menyampaikan pesan kognitif kepada calon pembeli. Faktor lain yang menentukan dalam desain produk adalah pemilihan text atau font yang digunakan. Font adalah contoh nyata bentuk berpengaruh terhadap persepsi (Kotler, 2003). Label yang dibuat harus

\section{KESIMPULAN DAN SARAN}

Kesimpulan dari Penelitian ini adalah sebagai berikut :

1. Dalam melakukan pengolahan Pembekuan Udang Merah terdapat beberapa tahap yang harus dilakukan yaitu penerimaan bahan baku, penimbangan, pencucian, pemotongan kepala, pencucian 2, penimbangan, sortasi, penyusunan, Pembekuan, dan pelabelan, serta pemasaran produk.

2. Desain kemasan yang baik dan benar adalah dengan memperhatikan

\section{DAFTAR PUSTAKA}

[SNI] Standar Nasional Indonesia 2014.Prosedur Pengolahan Udang Beku. SNI No. 2705:2014. Badan Stand arisasi Nasional.

Afrianto E, 2008. Pengawasan Mutu Bahan sesuai dengan Undang-Undang Nomor 7 Tahun 1996 tentang Pangan Pada pasal 30 ayat 2 disebutkan bahwa label, memuat sekurang-kurangnya keterangan mengenai :

1. Nama Produk

2. Daftar bahan yang digunakan

3. Berat berat atau isi bersih

4. Nama dan alamat pihak yang memproduksi

5. Tanggal, bulan dan tahun kadaluwarsa

Label dari Udang Merah ini di desain dengan menggunakan warna orange yang memiliki makna hangat, yaitu warna yang dapat menarik perhatian konsumen, selain itu juga diberi tulisan yang menarik serta barcode dan logo yang menambah daya tarik dari label ini. Pada tabel juga memenuhi syarat pelabelan. juga tersedia foto asli dari produk sehingga tidak mengecewakan pembeli karena tidak sesuai dengan harapan pembeli.

pemilihan warna, font, ukuran dan bahan yang tepat dan sesuai. Selain itu di dalam label juga harus terdapat beberapa keterangan seperti nama produk, daftar bahan yang digunakan, berat atau isi bersih, nama dan alamat pihak yang memproduksi atau memasukan pangan kedalam wilayah Indonesia dan tanggal, bulan dan tahun kadaluwarsa.

3.Usaha pembekuan udang merah (Paneus monodon) menguntungkan dan layak dilanjutkan.

atau Produk Pangan. Jakarta (ID) Direktorat Pembinaan Sekolah Menengah Kejurusan.

Andryan R. 2007. Vitamins and Nutrition is very important for humanbody. http://www.geocities.com/andryan_pwt ffoodsecret.html?20097 [d iakses pada 
SEMAH : Journal Pengelolaan Sumberdaya Perairan http://ojs.umb-bungo.ac.id/index.php/SEMAHJPSP

VOL. 4 No. 2

ISSN : 2580-0736

Desember 2020

tanggal 7 Juni 2009].

Briggs M., Simon F.S., R. Subasinghe, and M. Phillips. 2004. Introduction and movement of Penaeus vannamei and Penaeus stylirostris in Asia and the Pacific. FAO-UN. Bangkok.

Murniyati, A.S DAN Sunarman. 2000. Pendinginan, Pembekuan, dan Pengawetanikan.

Muzaki A. 2004. Produksi udang vaname (Litopenaeus vannamei) pada saat penebaran berbeda di tambak biocrete [skripsi]. Fakultas Perikanan dan Ilmu Kelautan, Institut Pertanian Bogor.

Pranoto SH.2007.Isolasi dan seleksi bakteri nitrifikasi dan denitrifikasi sebagai agen bioremediasi pada media pmeliharaan udang vannamei [skripsi]. Fakultas Perikanan dan Ilmu Kelautan, Institut Pertanian Bogor.

Prasetiyo KW. 2006. Pengolahan Limbah Cangkang Udang. http://biomateriallipi.org/?p=154 [diakses pada tanggal 7 Juni 2009].

Purwaningsih. S. 1993. Teknik Pembekuan Udang. Jakarta (ID). Penerbit Penebar Swadaya

Saleh. 2004. Evaluasi Gizi pada Pengolahan Bahan Pangan. Penerbit Institut Teknologi Bandung, Bandung. terus membaik. http://www.bisnis.com/servlet/page 